\title{
Adsorption and desorption behaviors of cetylpyridinium chloride on hydroxyapatite nanoparticles with different morphologies
}

\author{
Masahiro OKADA ${ }^{1}$, Daisuke HIRAMATSU1 ${ }^{1}$, Takumi OKIHARA² and Takuya MATSUMOTO ${ }^{1}$ \\ ${ }^{1}$ Department of Biomaterials, Graduate School of Medicine, Dentistry and Pharmaceutical Sciences, Okayama University, 2-5-1 Shikata-cho, Kita-ku, \\ Okayama 700-8558, Japan \\ ${ }^{2}$ Department of Applied Chemistry, Graduate School of Natural Science and Technology, Okayama University, 3-1-1 Tsushimanaka, Kita-ku, \\ Okayama 700-8558, Japan \\ Corresponding author, Takuya MATSUMOTO; E-mail: tmatsu@md.okayama-u.ac.jp
}

\begin{abstract}
Application of hydroxyapatite (HAp) nanoparticles to repair damaged enamel has attracted recent attention. In this study, HAp nanoparticles with various morphologies (spherical, short-rod, long-rod and fiber morphologies) were synthesized via chemical precipitation methods without the addition of template molecules, and the adsorption/desorption behaviors of a cationic antibacterial agent, cetylpyridinium chloride (CPC), on the HAp nanoparticles were evaluated. The adsorption of CPC on each HAp nanoparticle showed Langmuir-type adsorption, and the short-rod/long-rod HAp nanoparticles showed thermodynamically more stable adsorption of CPC than that with the spherical/fiber HAp nanoparticles. The desorption rate of CPC from the short-rod/long-rod HAp nanoparticles was slower than that of the spherical/fiber HAp nanoparticles. The HAp nanoparticles with different CPC release profiles presented here have potential applications as nanoparticulate enamel repair agents with antibacterial properties.
\end{abstract}

Keywords: Hydroxyapatite, Nanoparticle, Cetylpyridinium chloride, Antibacterial, Adsorption and desorption

\section{INTRODUCTION}

Various attempts have been undertaken to harden the enamel surfaces or to remineralize tooth enamel by using fluoride ${ }^{1)}$, metastable calcium phosphate $(\mathrm{CaP})$ solution $^{2}$, or acidic phosphate fluoride solution ${ }^{3)}$ treatments. Recently, the direct application of nanoparticulate hydroxyapatite (HAp) —one of the most widely used types of $\mathrm{CaP}$ materials ${ }^{4)}$ - for repairing (remineralizing or hardening) damaged enamel has attracted attention $^{5 \cdot 7)}$. For example, Huang et al. ${ }^{5)}$ demonstrated that HAp nanoparticles have a remineralization effect on initial caries lesions, similar to that of the fluoride. Furthermore, Li et al. ${ }^{6}$ ) showed that the hardening effect enhanced with the use of 20-nm HAp than that of the several hundred nanometer-sized HAp or 20-nm amorphous calcium phosphate (ACP).

Direct restorative materials (such as composite resins and glass ionomer cements) with antibacterial properties have been developed ${ }^{8-12}$ to avoid secondary caries resulting from plaque formation on restorative materials, which has been reported as the main cause of restoration failure ${ }^{13)}$. Thus, the incorporation of antibacterial properties into nanoparticulate repair agents should be an effective method to restore the damaged enamel and prevent the formation of secondary caries; however, there have been few reports on the subject to date.

Cetylpyridinium chloride (CPC) is a cationic quaternary ammonium salt that is widely used as the active component of oral antiseptics due to its broad antimicrobial spectrum with a particularly strong bactericidal effect against gram-positive bacteria ${ }^{14-16)}$. Namba et $a l .{ }^{11)}$ showed that a simple mixture of CPC with a light-curable resin led to growth inhibition of Streptococcus mutans attached to the resin surface, although no inhibitory effect was observed against bacteria that were not attached to the surface. Ehara et al. ${ }^{16)}$ developed a resin with recoverable antibacterial activity based on the desorption/adsorption of CPC by the ion-exchange mechanism.

The objective of the present study was to investigate the adsorption and desorption behaviors of CPC molecules on HAp nanoparticles with different morphologies that were prepared using a templatefree chemical precipitation method, in order to develop nanoparticulate enamel repair agents with antibacterial properties. We hypothesized that the adsorption capacity and desorption profile of CPC on HAp nanoparticles would be controllable by adjusting the morphology of the HAp nanoparticles.

\section{MATERIALS AND METHODS}

\section{Materials}

Unless otherwise stated, all materials were guaranteed reagent-grade and used as received from Wako Pure Chemical Industries (Osaka, Japan).

\section{HAp nanoparticles}

An aqueous solution of $\mathrm{Ca}\left(\mathrm{NO}_{3}\right)_{2} \cdot 6 \mathrm{H}_{2} \mathrm{O}(42 \mathrm{mM}, 800 \mathrm{~mL})$, whose initial $\mathrm{pH}$ (10.0 or 6.0) was adjusted by addition of $28 \%$ ammonia solution, was poured into a 1-L reactor equipped with an inlet for nitrogen and a magnetic stirrer. After the temperature in the reactor was equilibrated to a predetermined level $\left(25,50\right.$, or $\left.80^{\circ} \mathrm{C}\right)$, an aqueous solution of $\left(\mathrm{NH}_{4}\right)_{2} \mathrm{HPO}_{4}(100 \mathrm{mM}, 200 \mathrm{~mL})$ was added into the reactor, and the resultant mixture 
was stirred for another $24 \mathrm{~h}$ at the same temperature. The resulting product was then centrifugally washed (1,500 rpm; $10 \mathrm{~min}$ ) with distilled water until the $\mathrm{pH}$ of the solution became neutral, and was then redispersed in water. The aqueous dispersion (solid concentration, ca. 4 wt\%) was stored at room temperature, and used for the adsorption of CPC (see section Adsorption/desorption of $C P C$ ) without drying.

The dispersed sample was dried on an aluminum stub and coated using an osmium coater Neoc-Pro (Meiwafosis, Tokyo, Japan). The particle morphology was observed by scanning electron microscopy (SEM) using a JSM-6701F microscope (JEOL, Tokyo, Japan) operated at $5 \mathrm{kV}$. The number-averaged particle size $(n=50)$ was determined from SEM photographs with image analysis software (Image J, National Institutes of Health, Bethesda, MD, USA).

Fourier-transform infrared (FT-IR) spectra were obtained using an IRAffinity-1S system (Shimadzu, Kyoto, Japan) with a $\mathrm{KBr}$ pellet method at a resolution of $4 \mathrm{~cm}^{-1}$ with 32 scans. Prior to the measurements, the samples were dried under vacuum at $60^{\circ} \mathrm{C}$ for $15 \mathrm{~h}$.

Product identification was conducted by X-ray diffraction (XRD) measurements (RINT2500HF, Rigaku, Tokyo, Japan) equipped with a $\mathrm{Cu}-\mathrm{K} \alpha$ radiation source.

The specific surface area was determined with the nitrogen adsorption technique using a BrunauerEmmett-Teller NOVA-3000 micropore analyzer (Quantachrome Instruments, Boynton Beach, FL, USA). The samples were dried under reduced pressure at room temperature for 2 days, and were degassed at $40^{\circ} \mathrm{C}$ for 2 $\mathrm{h}$ just before the measurements were taken.

The $\mathrm{Ca} / \mathrm{P}$ atomic ratio of each $\mathrm{HAp}$ nanoparticle was measured by inductively coupled plasma-atomic emission spectrometry (ICP-AES, SPS4000, Seiko Instruments, Chiba, Japan). Commercially available calcium and phosphorus standard solutions were used to obtain the standard curves for ICP-AES measurements.

\section{Adsorption / desorption of CPC}

The aqueous dispersion of HAp nanoparticles (solid content, $0.020 \mathrm{~g}$ ) was mixed with a $\mathrm{CPC}$ aqueous solution in a test tube, and the $\mathrm{CPC}$ concentration was set to 0.5 , $1.0,1.5,3.0$, or $5.0 \mathrm{mmol} / \mathrm{L}$ (total, $4 \mathrm{~mL}$ ). The test tube was soaked in a water bath at room temperature for 24 $\mathrm{h}$, and then the CPC-adsorbed HAp nanoparticles were dried after centrifugal separation (3,500 rpm, $5 \mathrm{~min}$ ) followed by washing with distilled water. The dried nanoparticles were dissolved in an $\mathrm{HCl}$ solution $(\mathrm{pH} 1)$, and the amount of CPC adsorbed was determined by measuring the ultraviolet (UV) absorption $(\lambda=258 \mathrm{~nm})$ of the solution with a UV/Vis spectrophotometer (DU730, Beckman Coulter, Brea, CA, USA).

In order to evaluate the desorption behavior of CPC on the HAp nanoparticles, the CPC-adsorbed HAp nanoparticles were prepared according to the procedure described above (0.2 g HAp; $40 \mathrm{~mL}$ of $3.0 \mathrm{mmol} / \mathrm{L} \mathrm{CPC})$. A portion $(0.025 \mathrm{~g})$ of the dried CPC-adsorbed HAp nanoparticles was dispersed in $5.0 \mathrm{~mL}$ of phosphatebuffered saline (PBS) and then the PBS dispersion in a test tube was placed in a water bath at $37^{\circ} \mathrm{C}$ for several days. The supernatant was separated from the PBS dispersion by centrifugation (3,500 rpm, $5 \mathrm{~min}$ ) and was collected, and the precipitation was redispersed in fresh PBS on day 1, 3, 5, and 7. The amount of CPC desorbed was determined by measuring the UV absorption $(\lambda=258 \mathrm{~nm})$ of the supernatant with a UV/Vis spectrophotometer (DU730).

The adsorption or desorption test was repeated 4 times, and the data obtained are represented as means \pm standard deviations (SDs).

\section{RESULTS}

\section{Preparation of HAp nanoparticles}

Figure 1 shows the XRD patterns of the samples obtained by the chemical precipitation method under different conditions. Under the alkaline conditions (initial pH, 10.0; Fig. 1a-c), the XRD patterns indicated the formation of HAp (JCPDS PDF No. 9-732), and broadened peaks were observed for the powder formed at low temperature $\left(25^{\circ} \mathrm{C}\right)$. Under the acidic conditions (initial pH, 6.0), a HAp phase was only observed for the powder formed at $80^{\circ} \mathrm{C}$ (Fig. 1f), whereas no HAp phase was observed at lower temperature, although octacalcium phosphate (OCP; JCPDS PDF No. 26-1056) and dicalcium phosphate dihydrate (DCPD; JCPDS PDF No. 9-77) were formed (Fig. 1d and e).

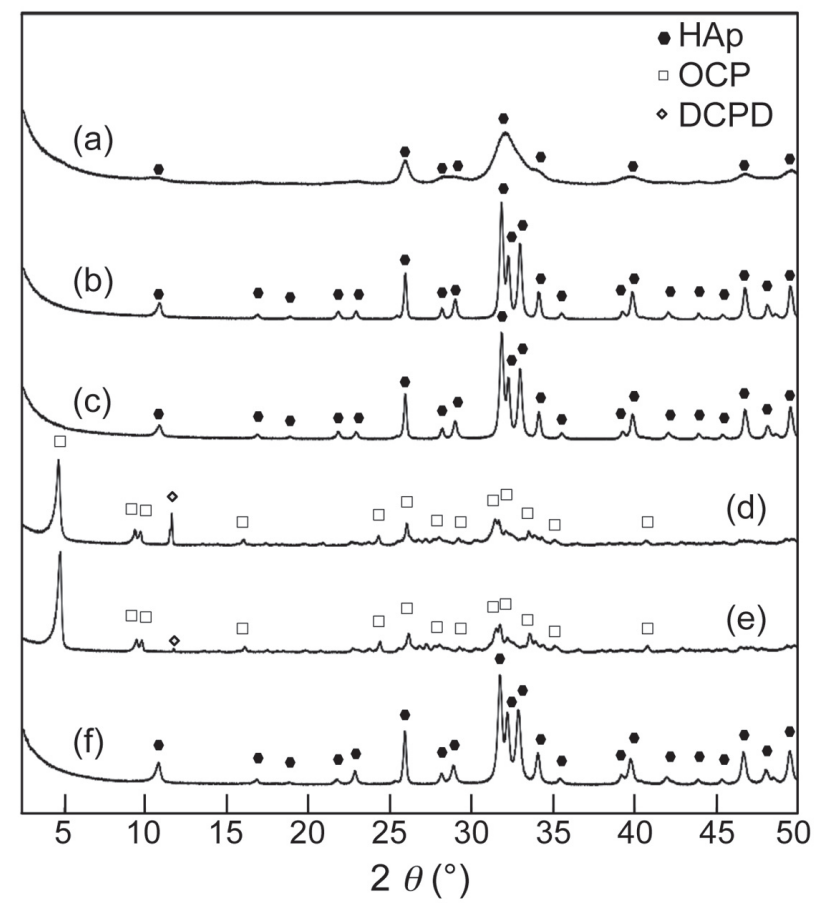

Fig. 1 XRD patterns of the samples prepared by a chemical precipitation process at an initial $\mathrm{pH}$ of $(\mathrm{a}-\mathrm{c}) 10$ or $(\mathrm{d}-\mathrm{f}) 6$ and at a reaction temperature of (a, d) $25^{\circ} \mathrm{C}$, (b, e) $50^{\circ} \mathrm{C}$, or (c, f) $80^{\circ} \mathrm{C}$. 
Figure 2 shows the SEM photographs of the obtained samples. Under the alkaline conditions, 17-nm-sized spherical nanoparticles were observed for the sample formed at $25^{\circ} \mathrm{C}$ (Fig. 2a), and rod-shaped nanoparticles (154 $\mathrm{nm}$ in the long axis, $13 \mathrm{~nm}$ in the short axis) were observed for the sample formed at $50^{\circ} \mathrm{C}$ (Fig. $2 \mathrm{~b}$ ). Elongated rod-shaped nanoparticles $(585 \mathrm{~nm}$ in the long axis, $43 \mathrm{~nm}$ in the short axis) were formed under the alkaline conditions at $80^{\circ} \mathrm{C}$ (Fig. 2c), whereas more elongated nanofibers $(3,550 \mathrm{~nm}$ in the long axis, $48 \mathrm{~nm}$ in the short axis) were formed under the acidic conditions at $80^{\circ} \mathrm{C}$ (Fig. 2f). Hereafter, these HAp nanoparticles are referred to as spherical (alkaline; $25^{\circ} \mathrm{C}$ ), short-rod (alkaline; $50^{\circ} \mathrm{C}$ ), long-rod (alkaline; $80^{\circ} \mathrm{C}$ ), and fiber (acidic; $80^{\circ} \mathrm{C}$ ) HAp, respectively. Note that the crystal habit of the long-rod HAp was a hexagonal prism, whereas that of the fiber HAp was blade-shaped. The OCP/DCPD particles obtained under the acidic conditions at lower temperatures showed micron-sized blade-shaped morphologies (Figs. 2d and 2e).

The specific surface areas and $\mathrm{Ca} / \mathrm{P}$ ratios of the four kinds of HAp nanoparticles prepared under different conditions are summarized in Table 1. The specific surface area was the largest for the HAp sample formed at low temperature (spherical HAp) and decreased with an increase in synthesis temperature under the
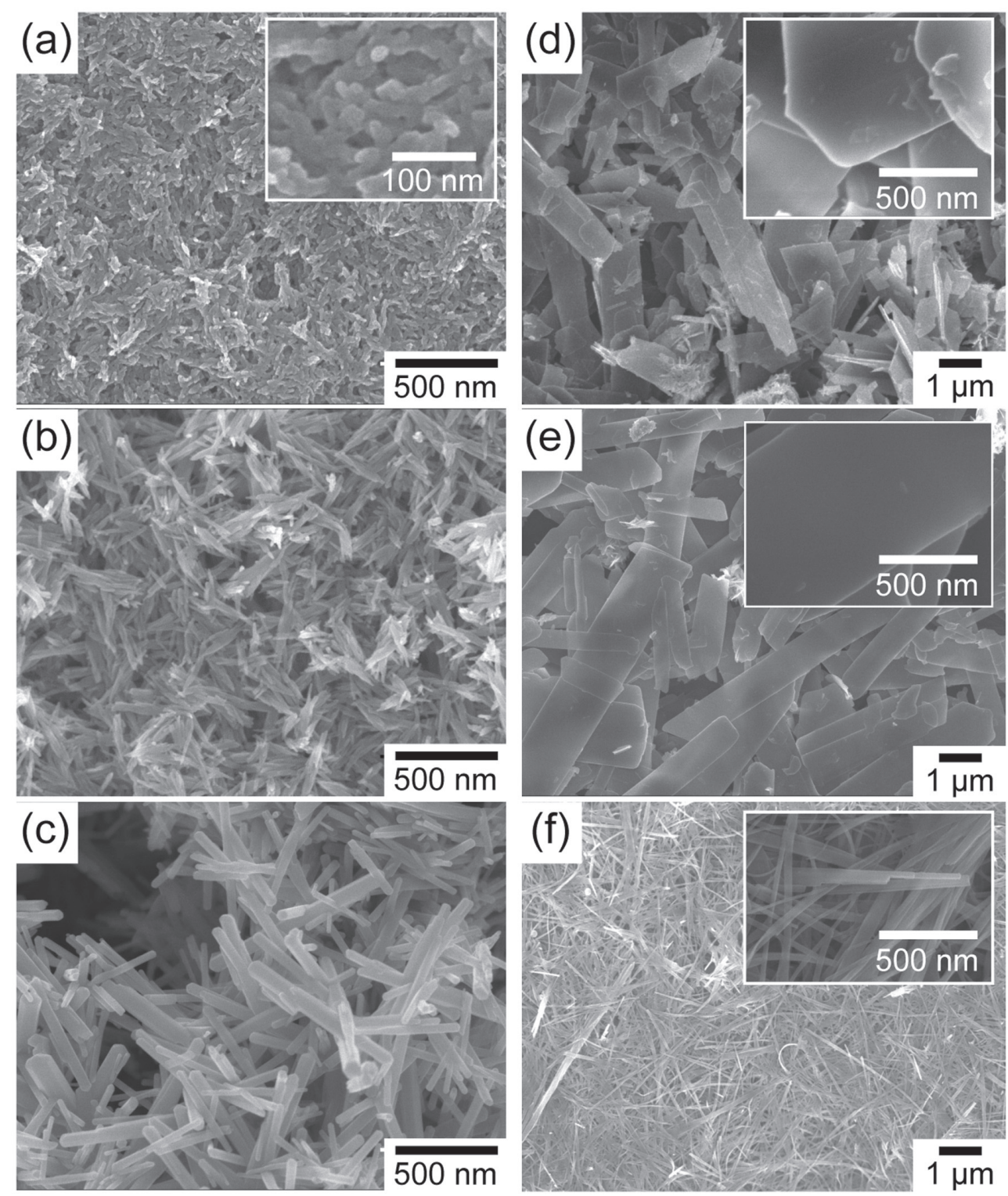

Fig. 2 SEM photographs of the samples prepared by a chemical precipitation process at an initial $\mathrm{pH}$ of $(\mathrm{a}-\mathrm{c}) 10$ or $(\mathrm{d}-\mathrm{f}) 6$ and at a reaction temperature of $(\mathrm{a}, \mathrm{d}) 25^{\circ} \mathrm{C},(\mathrm{b}, \mathrm{e}) 50^{\circ} \mathrm{C}$, or $(\mathrm{c}, \mathrm{f}) 80^{\circ} \mathrm{C}$. 
Table 1 Ca/P molar ratios, specific surface areas $(S)$ of the hydroxyapatite (HAp) nanoparticles with different morphologies, equilibrium constants $(a)$, and saturated adsorption density $\left(\Gamma_{m}\right)$ for cetylpyridinium chloride $(\mathrm{CPC})$ adsorption

\begin{tabular}{lcccc}
\hline & Spherical HAp & Short-rod HAp & Long-rod HAp & Fiber HAp \\
\hline $\mathrm{Ca} / \mathrm{P}\left(\right.$ molar ratio) ${ }^{\mathrm{a})}$ & $1.54 \pm 0.01$ & $1.62 \pm 0.01$ & $1.63 \pm 0.02$ & $1.60 \pm 0.02$ \\
$\mathrm{~S}\left(\mathrm{~m}^{2} / \mathrm{g}\right)^{\mathrm{b})}$ & $119.2 \pm 16.0$ & $48.5 \pm 9.6$ & $31.2 \pm 6.6$ & $34.6 \pm 4.5$ \\
$\mathrm{a}(\mathrm{L} / \mu \mathrm{mol})^{\mathrm{c})}$ & 1.40 & 2.81 & 2.73 & 1.41 \\
$\Gamma_{\mathrm{m}}\left(\mu \mathrm{mol} / \mathrm{m}^{2}\right)^{\mathrm{c})}$ & 1.06 & 2.10 & 2.67 & 0.58 \\
\hline
\end{tabular}

a) Determined form ICP-AES measurements; presented as means \pm SD $(n=3)$

b) Determined from Brunauer-Emmett-Teller measurements; presented as means \pm SD $(n=3)$

c) Calculated from the intercept and the slope of the $1 / C$ and $1 / \Gamma$ plots shown in Fig. 5 .

alkaline conditions. The specific surface area of the fiber HAp was slightly larger than that of the long-rod HAp. The Ca/P molar ratio of all of the HAp samples prepared in this study was lower than that predicted by the stoichiometry of HAp $\left(\mathrm{Ca}_{10}\left(\mathrm{PO}_{4}\right)_{6}(\mathrm{OH})_{2} ; \mathrm{Ca} / \mathrm{P}\right.$ molar ratio=10/6), indicating the formation of calcium-deficient HAp. The short-rod and the long-rod HAp showed relatively larger $\mathrm{Ca} / \mathrm{P}$ values, whereas the spherical and fiber HAp showed lower $\mathrm{Ca} / \mathrm{P}$ values.

As shown in the FT-IR spectra in Fig. 3, the IR absorptions due to $\mathrm{OH}^{-}$and $\mathrm{PO}_{4}{ }^{3-}$ in a typical HAp structure ${ }^{17,18)}$ were observed in all of the HAp nanoparticles prepared under different conditions. In brief, the peaks at 3,573 and $632 \mathrm{~cm}^{-1}$ were attributed to $\mathrm{O}-\mathrm{H}$ stretching vibrations in the $\mathrm{HAp}$ lattice, respectively, and the characteristic peaks due to $\mathrm{PO}_{4}^{3-}$ absorptions were found at 1092/1045 $\left(v_{3} \mathrm{PO}_{4}{ }^{3-}\right), 963$ $\left(v_{1} \mathrm{PO}_{4}{ }^{3-}\right), 603 / 572\left(v_{4} \mathrm{PO}_{4}{ }^{3-}\right)$, and $474\left(v_{2} \mathrm{PO}_{4}{ }^{3-}\right) \mathrm{cm}^{-1}$. In the FT-IR spectrum of the fiber HAp shown in Fig. 3d, additional peaks at $1,209 / 860 \mathrm{~cm}^{-1}$ and a broad band at around $1,140 \mathrm{~cm}^{-1}$ were observed, which were likely due to the presence of $\mathrm{HPO}_{3}{ }^{2-19)}$. Bands at 1,456/1,413 and $877 \mathrm{~cm}^{-1}$ were attributed to $\mathrm{CO}_{3}{ }^{2-}$-substituted phosphate positions in the HAp lattice ${ }^{20)}$.

\section{Adsorption and desorption of $C P C$}

Figure 4 shows the amount of CPC adsorbed on the HAp nanoparticles from aqueous solutions of CPC at a constant mixing ratio of HAp to the solution. The amount of CPC on the HAp nanoparticles increased rapidly for initial CPC concentrations up to $1.5 \mathrm{mmol} / \mathrm{L}$, and then increased gradually at higher initial concentrations. The amount of adsorption of CPC for each HAp type was observed in the following order: spherical>short$\operatorname{rod}>$ long-rod>fiber HAp. The reciprocal numbers of the equilibrium concentration of CPC in the solution $(C)$ and the adsorbed amount of $\mathrm{CPC}(\Gamma)$ obtained from Fig. 4 are plotted in Fig. 5. The $1 / \Gamma$ value obtained at the lowest $C$ was excluded because of its large deviation even in the case of small deviation of $\Gamma$. Each plot shows a linear relationship, indicating that the CPC adsorption behaviors on the four kinds of HAp nanoparticles fit with a Langmuir adsorption model ${ }^{21)}$ under the conditions

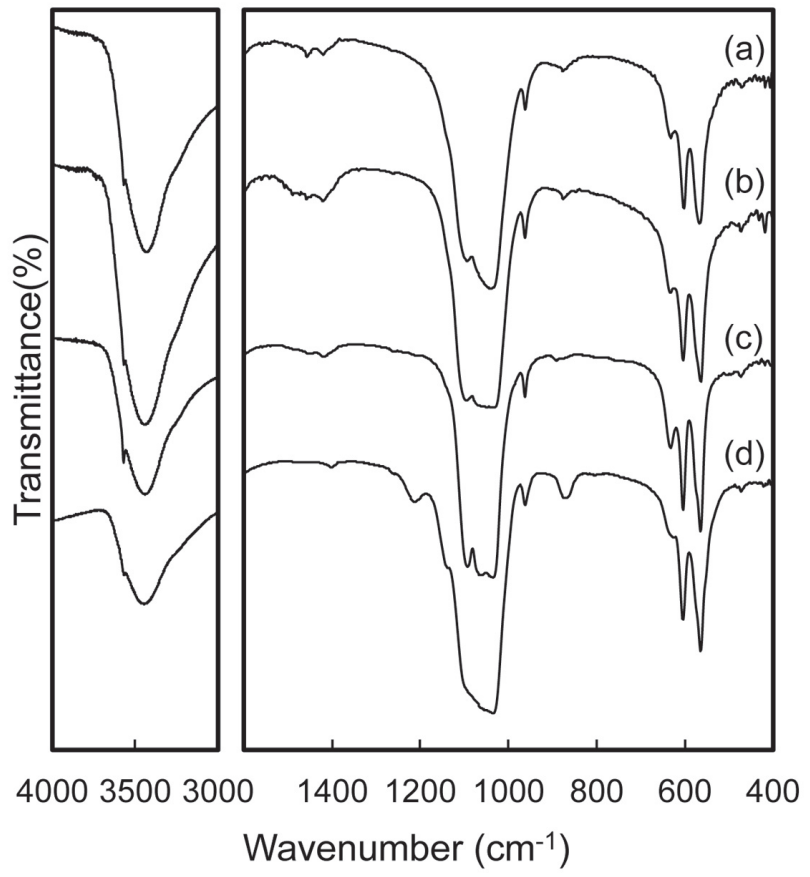

Fig. 3 FT-IR spectra of HAp nanoparticles with different morphologies: (a) spherical; (b) short-rod; (c) longrod; and (d) fiber.

applied in this study. According to the Langmuir model, the saturated adsorption amount of CPC on each HAp $\left(\Gamma_{m}\right)$ and the equilibrium constants $(a)$ were calculated from the following equation ${ }^{21)}$ :

$$
1 / \Gamma=1 / \Gamma_{m}+\left(1 / a \Gamma_{m}\right) \times 1 / C
$$

The calculated values are summarized in Table 1 . The $\Gamma_{m}$ value of long-rod HAp was the highest among the four types, and closely corresponded with the reported surface density of CPC $\left(2.14-2.75 \mu \mathrm{mol} / \mathrm{m}^{2}\right)$ at the airwater interface in the presence of electrolytes $(\mathrm{NaCl})$ at $25^{\circ} \mathrm{C}^{22)}$. The $\Gamma_{m}$ value decreased in the following order: 


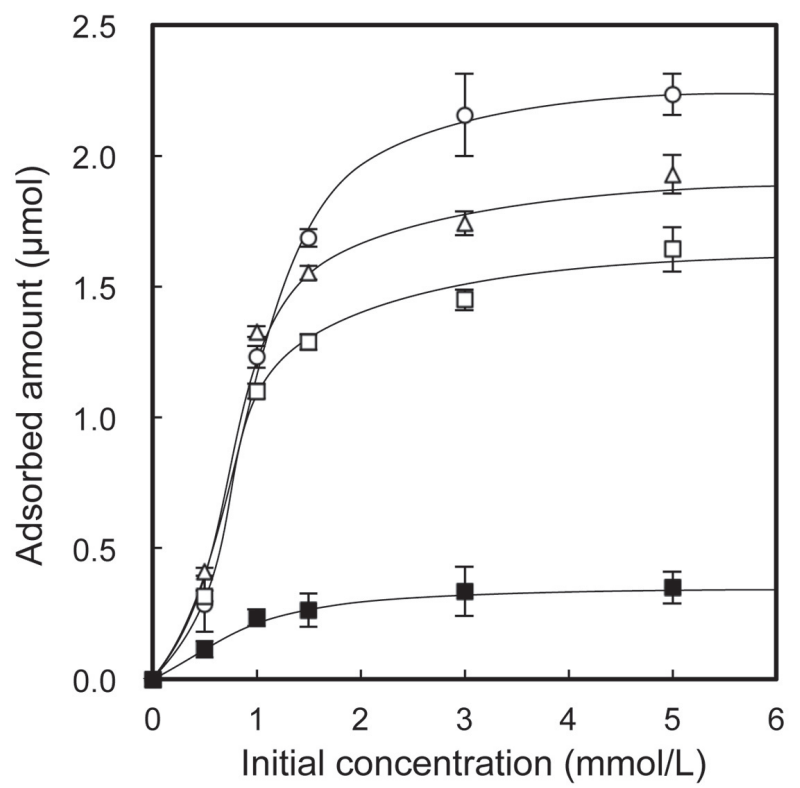

Fig. 4 Relationships between initial concentration and the absorbed amount of CPC on HAp nanoparticles with different morphologies: open circles, spherical; open triangles, short-rod; open squares, long-rod; closed squares, fiber.

The adsorption tests were conducted in distilled water at $25^{\circ} \mathrm{C}(n=4)$.

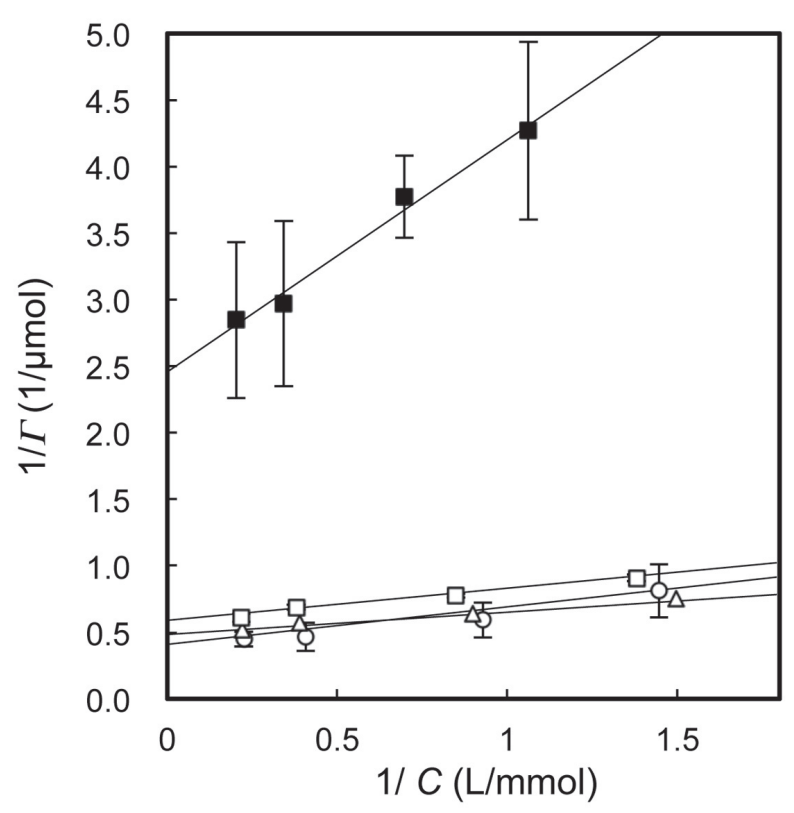

Fig. 5 Langmuir plots for the CPC adsorption onto HAp nanoparticles with different morphologies: open circles, spherical; open triangles, short-rod; open squares, long-rod; closed squares, fiber.

$C$ is the equilibrium concentration of $\mathrm{CPC}$ in the solution, and $\Gamma$ is the amount of CPC absorbed on each HAp. The adsorption tests were conducted in distilled water at $25^{\circ} \mathrm{C}(n=4)$.

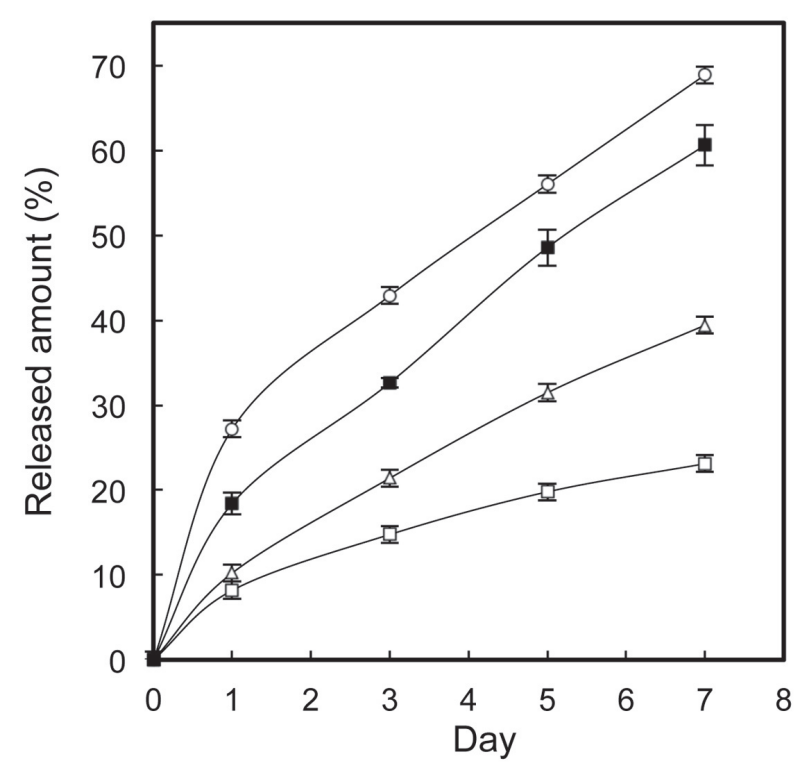

Fig. 6 Desorption profiles of CPC from the surfaces of HAp nanoparticles with different morphologies: open circles, spherical; open triangles, short-rod; open squares, long-rod; closed squares, fiber. The desorption tests were conducted in PBS at $37^{\circ} \mathrm{C}(n=4)$.

long-rod $>$ short-rod $>$ spherical>fiber. The equilibrium constants of short-rod and long-rod HAp showed larger values compared with those of spherical and fiber HAp, indicating that the adsorption of CPC onto short-rod and long-rod HAp is thermodynamically more stable as compared with that onto spherical and fiber HAp.

Figure 6 shows the desorption profiles of CPC from the HAp surfaces in PBS at $37^{\circ} \mathrm{C}$. The CPC molecules adsorbed on the HAp surfaces were gradually released into the aqueous media in all cases. The release rate was in the following order: spherical $>$ fiber $>$ short-rod $>$ long rod.

\section{DISCUSSION}

HAp belongs to a hexagonal crystal system ${ }^{23)}$, and hence HAp surfaces exhibit anisotropic characteristics, including anisotropic adsorption profiles, according to the crystal morphology ${ }^{24)}$. The morphology of HAp nanoparticles can be manipulated by adding template additives (such as surfactant molecules ${ }^{25,26)}$ and amino acids ${ }^{27-30)}$ ). This variation is mainly due to the inhibition of crystal growth from preferential adsorption of the template molecules onto the HAp surface. Therefore, these template molecules also affect the adsorption/ desorption characteristics of the post-added molecules on HAp surfaces.

In this study, we prepared HAp nanoparticles with various morphologies via a chemical precipitation 
process without the use of template molecules. Chemical precipitation methods have been widely used for preparing HAp nanoparticles because they are simple and cost-effective. Simple mixing of two aqueous solutions of calcium and orthophosphate results in the formation of highly supersaturated solutions for HAp, which induces the rapid precipitation of HAp nanoparticles ${ }^{31}$. The morphology of HAp nanoparticles depends on the precipitation conditions applied, such as the concentration of reactants, ionic strength, $\mathrm{pH}$, and temperature ${ }^{31,32)}$. The morphology of amorphous nanoparticles is generally spherical, whereas that of crystalline nanoparticles is determined thermodynamically or kinetically according to the surface energy or reaction rate constant of each crystalline plane ${ }^{33)}$. In this study, chemical precipitation under the alkaline conditions at low temperature $\left(25^{\circ} \mathrm{C}\right)$ resulted in the formation of spherical nanoparticles, which was likely due to the formation of ACP, as it has no specific crystalline planes and a relatively low $\mathrm{Ca} / \mathrm{P}$ ratio at the initial stage ${ }^{34)}$. The increase in preparation temperature led to the formation of rod-shaped nanocrystals with a crystal structure of a hexagonal prism. The $a$-plane of the HAp crystal shows smaller interfacial energy in aqueous medium compared with the $c$-plane ${ }^{35)}$, which leads to the formation of elongated hexagonal prisms. Under acidic conditions (initial $\mathrm{pH}$, 6.0), the $\mathrm{pH}$ of the aqueous dispersion decreased due to the formation of HAp. In this study, lower temperature $\left(25\right.$ or $50^{\circ} \mathrm{C}$ ) led to the formation of DCPD and OCP, which are stable calcium phosphate phases in the acidic condition ${ }^{36)}$. The higher temperature $\left(80^{\circ} \mathrm{C}\right)$ led to the formation of only the HAp phase with fibrous morphologies. This might occur because HAp initially precipitated at high temperature at the initial $\mathrm{pH}$ of $6.0^{37)}$ and then the HAp crystal grew epitaxially, or because fibrous OCP nanocrystals were initially formed and then hydrolyzed into HAp crystals ${ }^{38)}$ during the high temperature treatment at $80^{\circ} \mathrm{C}$. The resultant fiber HAp had a lower $\mathrm{Ca} / \mathrm{P}$ ratio as compared with that of the rodshaped HAp prepared under alkaline conditions, which indicates that calcium ions were exchanged with protons under acidic conditions; hence, $\mathrm{HPO}_{3}{ }^{2-}$ was observed in the FT-IR spectrum.

In this study, we conducted the adsorption tests under constant amounts of HAp nanoparticles, and analyzed the adsorption behaviors with a Langmuir adsorption model, where the adsorbed amount of CPC was normalized by the surface area of the nanoparticles used (Table 1). Note that the HAp nanoparticles used for the adsorption tests in this study should be weakly flocculated ${ }^{39}$, and the drying of the nanoparticle dispersion generally induces the formation of severe aggregation that decreases the surface area of the nanoparticles ${ }^{34,40)}$. Therefore, the nanoparticles for CPC adsorption tests were used without drying after the preparation. The cationic cetylpyridinium ions should be adsorbed onto HAp through ionic interactions with anions on the HAp surfaces. The surface ion composition (and hence the surface charge) of HAp in aqueous medium varies according to the ion composition of the medium, and HAp surfaces show negative charges in aqueous media under neutral $\mathrm{pH}^{41}$. The deviation of the $\mathrm{Ca} / \mathrm{P}$ ratio from the stoichiometric value $(\mathrm{Ca} / \mathrm{P}$ molar ratio $=10 / 6$ ) would also result in a decrease in the negative surface charge on the HAp surface in an aqueous medium ${ }^{42}$ due to an increase in the solubility of $\mathrm{HAp}^{41)}$ and the degree of re-adsorption of $\mathrm{PO}_{4}{ }^{3-}$ ions onto the HAp surface ${ }^{43}$. In this study, the CPC adsorption onto the HAp nanoparticles with different morphologies showed a Langmuir-type adsorption. The $a$ and $\Gamma_{m}$ values of short-rod and long-rod HAp nanoparticles were larger compared with those of spherical and fiber HAp, indicating that a rod-shaped morphology supports a thermodynamically stable interaction between CPC and HAp with larger negative surface charges. Note that the critical micelle concentration (CMC) of CPC is around $0.9 \mathrm{mmol} / \mathrm{L}$ in pure water at $25^{\circ} \mathrm{C}^{22)}$. Therefore, CPC molecules seem to exist as monomeric surfactant molecules at $0.5 \mathrm{mmol} / \mathrm{L}$ of $\mathrm{CPC}$, whereas micelles formed above $1.0 \mathrm{mmol} / \mathrm{L}$ in this study. Atkin et al. investigated the adsorption kinetics and structural arrangements of cetylpyridinium bromide $(\mathrm{CPBr})$ at the silica-aqueous interface ${ }^{44)}$, and they found that $\mathrm{CPBr}$ micelles adsorb directly to the silica surface above CMC and this is reflected in the structure of the surface layer. In this study, although we used the HAp nanoparticles, which have larger amount of ionic species as compared with silica and are slightly soluble in water, CPC micelles were likely to adsorb directly onto HAp surfaces above CMC. In order to fully understand the adsorption state of CPC on each kind of HAp surface, it is necessary to observe the morphology of CPC layer on each HAp surface.

The desorption tests were conducted with the CPCloaded HAp nanoparticles prepared under the constant and relatively high CPC concentrations $(3.0 \mathrm{mM}$; above CMC) in order to evaluate the desorption behaviors of CPC from HAp nanoparticles with high loading amount of cationic antibacterial agents. The desorption behaviors of CPC were also different among the HAp nanoparticles with different morphologies; thus, the release rate of antibacterial CPC from HAp nanoparticles can be controlled by manipulating their morphologies. The short-rod and long-rod HAp nanoparticles showed slower desorption rates, indicating a thermodynamically stable interaction of CPC and HAp that was favorable for the slow release of antibacterial CPC molecules. Note that $\mathrm{CPC}$ interacts with each other via a hydrophobic interaction, which should also cause the slowest desorption rate of the long-rod HAp that showed the highest surface density of CPC (Table 1).

Although the nanoparticles of $\mathrm{CaP}$, including HAp, have been widely studied as filler materials for non-resolvable materials such as resin matrices ${ }^{10,45}$, the mechanical properties of CaP-filled resins will change owing to the dissolvability of $\mathrm{CaP}$ under acidic $\mathrm{pH}$ conditions. Recently, direct application of HAp nanoparticles to repair damaged enamel has attracted attention because of its dissolvability (i.e., the 
remineralization effect due to the release of calcium and phosphate ions $s^{46,47)}$ and a neutralization effect $\left.{ }^{48}\right)$. The HAp nanoparticles with controlled CPC release profiles developed in this study show potential applications as enamel repair agents to restore the damaged enamel and prevent the formation of secondary caries.

\section{CONCLUSIONS}

The morphology of HAp nanoparticles can be varied via simple and cost-effective chemical precipitation methods without requiring the addition of template molecules, which remain and cover the HAp surfaces. The adsorption and desorption behavior of CPC on HAp nanoparticles depends on the morphology of the HAp nanoparticles, and the rod-shaped HAp nanoparticles resulted in a thermodynamically stable interaction between CPC and HAp. The antibacterial-modified HAp nanoparticles with different CPC release profiles presented here show potential applications as enamel repair agent for damaged enamel.

\section{ACKNOWLEDGMENTS}

This work was supported in part by Japan Society for the Promotion of Science KAKENHI Grant Numbers 25220912,25293402 and 25462977.

\section{REFERENCES}

1) Aoba T. The effect of fluoride on apatite structure and growth. Crit Rev Oral Biol Med 1997; 8: 136-153.

2) Hsu CC, Chung HY, Yang JM, Shi W, Wu B. Influences of ionic concentration on nanomechanical behaviors for remineralized enamel. J Mech Behav Biomed Mater 2011; 4: 1982-1989.

3) Yamagishi K, Onuma K, Suzuki T, Okada F, Tagami J, Otsuki M, Senawangse P. Materials chemistry: a synthetic enamel for rapid tooth repair. Nature 2005; 433: 819.

4) Okada M, Matsumoto T. Synthesis and modification of apatite nanoparticles for use in dental and medical applications. Jpn Dent Sci Rev 2015; 51: 85-95.

5) Huang SB, Gao SS, Yu HY. Effect of nano-hydroxyapatite concentration on remineralization of initial enamel lesion in vitro. Biomed Mater 2009; 4: 034104.

6) Li L, Pan H, Tao J, Xu X, Mao C, Gu X, Tang R. Repair of enamel by using hydroxyapatite nanoparticles as the building blocks. J Mater Chem 2008; 18: 4079-4084.

7) Besinis A, De Peralta T, Tredwin CJ, Handy RD. Review of nanomaterials in dentistry: interactions with the oral microenvironment, clinical applications, hazards, and benefits. ACS Nano 2015; 9: 2255-2289.

8) Feng J, Cheng L, Zhou X, Xu HH, Weir MD, Meyer M, Maurer H, Li Q, Hannig M, Rupf S. In situ antibiofilm effect of glass-ionomer cement containing dimethylaminododecyl methacrylate. Dent Mater 2015; 31: 992-1002.

9) Imazato $\mathrm{S}, \mathrm{Ma} \mathrm{S}$, Chen $\mathrm{JH}, \mathrm{Xu} \mathrm{HH}$. Therapeutic polymers for dental adhesives: loading resins with bio-active components. Dent Mater 2014; 30: 97-104.

10) Cheng L, Weir MD, Zhang K, Wu EJ, Xu SM, Zhou X, Xu HH. Dental plaque microcosm biofilm behavior on calcium phosphate nanocomposite with quaternary ammonium. Dent Mater 2012; 28: 853-862.

11) Namba N, Yoshida $Y$, Nagaoka N, Takashima S, MatsuuraYoshimoto K, Maeda H, Van Meerbeek B, Suzuki K,
Takashiba S. Antibacterial effect of bactericide immobilized in resin matrix. Dent Mater 2009; 25: 424-430.

12) Imazato S. Bio-active restorative materials with antibacterial effects: new dimension of innovation in restorative dentistry. Dent Mater J 2009; 28: 11-19.

13) Deligeorgi V, Mjor IA, Wilson NH. An overview of reasons for the placement and replacement of restorations. Primary Dent Care 2001; 8: 5-11.

14) Radford JR, Beighton D, Nugent Z, Jackson RJ. Effect of use of $0.05 \%$ cetylpyridinium chloride mouthwash on normal oral flora. J Dent 1997; 25: 35-40.

15) Gjorgievska E, Apostolska S, Dimkov A, Nicholson JW, Kaftandzieva A. Incorporation of antimicrobial agents can be used to enhance the antibacterial effect of endodontic sealers. Dent Mater 2013; 29: e29-e34.

16) Ehara A, Torii M, Imazato S, Ebisu S. Antibacterial activities and release kinetics of a newly developed recoverable controlled agent-release system. J Dent Res 2000; 79: 824828.

17) Fowler BO. Infrared studies of apatites. I. Vibrational assignments for calcium, strontium, and barium hydroxyapatites utilizing isotopic substitution. Inorg Chem 1974; 13: 194-207.

18) Taylor MG, Parker SF, Simkiss K, Mitchell PCH. Bone mineral: evidence for hydroxy groups by inelastic neutron scattering. Phys Chem Chem Phys 2001; 3: 1514-1517.

19) Koutsopoulos S. Synthesis and characterization of hydroxyapatite crystals: a review study on the analytical methods. J Biomed Mater Res 2002; 62: 600-612.

20) Emerson WH, Fisher EE. The infrared absorption spectra of carbonate in calcified tissue. Arch Oral Biol 1962; 7; 671683.

21) Jönsson B, Lindman B, Holmberg K, Kronberg B. Surfactant and polymers in aqueous solution. Wiley, Chichester, 1998.

22) Mukhim T, Ismail K. Micellization of cetylpyridinium chloride in aqueous lithium chloride, sodium chloride and potassium chloride media. J Surface Sci Technol 2005; 21: 113-127.

23) Elliott JC. Structure and chemistry of the apatites and other calcium orthophosphates amsterdam: Elsevier, 1994.

24) Kawasaki T. Hydroxyapatite as a liquid chromatographic packing. J Chromatogr A 1991; 544: 147-184.

25) Liu Y, Hou D, Wang G. A simple wet chemical synthesis and characterization of hydroxyapatite nanorods. Mater Chem Phys 2004; 86: 69-73.

26) Shanthi PMSL, Ashok M, Balasubramanian T, Riyasdeen A, Akbarsha MA. Synthesis and characterization of nanohydroxyapatite at ambient temperature using cationic surfactant. Mater Lett 2009; 63: 2123-2125.

27) Sharma R, Pandey RR, Gupta AA, Kar S, Dhayal M. In situ amino acid functionalization and microstructure formation of hydroxyapatite nanoparticles synthesized at different $\mathrm{pH}$ by precipitation route. Mater Chem Phys 2012; 133: 718-725.

28) Gonzalez-McQuire R, Chane-Ching JY, Vignaud E, Lebugle A, Mann S. Synthesis and characterization of amino acidfunctionalized hydroxyapatite nanorods. J Mater Chem 2004; 14: 2277-2281.

29) Matsumoto T, Okazaki M, Nakahira A, Sasaki J, Egusa H, Sohmura T. Modification of apatite materials for bone tissue engineering and drug delivery carriers. Curr Med Chem 2007; 14: 2726-2733.

30) Matsumoto T, Okazaki M, Inoue M, Hamada Y, Taira M, Takahashi J. Crystallinity and solubility characteristics of hydroxyapatite adsorbed amino acid. Biomaterials 2002; 23: 2241-2247.

31) Ferraz MP, Monteiro FJ, Manuel CM. Hydroxyapatite nanoparticles: A review of preparation methodologies. J Appl Biomater Biomech 2004; 2: 74-80.

32) Lee WH, Zavgorodniy AV, Loo CY, Rohanizadeh R. Synthesis and characterization of hydroxyapatite with different 
crystallinity: Effects on protein adsorption and release. J Biomed Mater Res A 2012; 100: 1539-1549.

33) Tao AR, Habas S, Yang P. Shape control of colloidal metal nanocrystals. Small 2008; 4: 310-325.

34) Okada M, Furuzono T. Low-temperature synthesis of nanoparticle-assembled, transparent, and low-crystallized hydroxyapatite blocks. J Colloid Interface Sci 2011; 360: 457462.

35) Zhao W, Xu Z, Yang Y, Sahai N. Surface energetics of the hydroxyapatite nanocrystal-water interface: A molecular dynamics study. Langmuir 2014; 30: 13283-13292.

36) Suzuki O. Octacalcium phosphate: Osteoconductivity and crystal chemistry. Acta Biomater 2010; 6: 3379-3387.

37) Monma H, Ueno S, Kanazawa T. Properties of hydroxyapatite prepared by the hydrolysis of tricalcium phosphate. J Chem Tech Biotechnol 1981; 31: 15-24.

38) Miyatake $\mathrm{N}$, Kishimoto KN, Anada T, Imaizumi H, Itoi E, Suzuki O. Effect of partial hydrolysis of octacalcium phosphate on its osteoconductive characteristics. Biomaterials 2009; 30: 1005-1014

39) Fujii S, Okada M, Furuzono T. Hydroxyapatite nanoparticles as stimulus-responsive particulate emulsifiers and building block for porous materials. J Colloid Interface Sci 2007; 315: 287-296.

40) Rahman IA, Vejayakumaran P, Sipaut CS, Ismail J, Chee CK. Effect of the drying techniques on the morphology of silica nanoparticles synthesized via sol-gel process. Ceram Int 2008; 34: 2059-2066.

41) Somasundaran P, Wang YHC. Surface chemicalcharacteristics and adsorption properties of apatite. In: Misra DN editor.
Adsorption on and surface chemistry of hydroxyapatite. New York: Plenum; 1984. p. 129-149.

42) Suzuki T, Yamamoto T, Toriyama M, Nishizawa K, Yokogawa Y, Mucalo MR, Kawamoto Y, Nagata F, Kameyama T. Surface instability of calcium phosphate ceramics in tissue culture medium and the effect on adhesion and growth of anchoragedependent animal cells. J Biomed Mater Res 1997; 34: 507517.

43) Bengtsson Å, Shchukarev A, Persson P, Sjöberg S. A solubility and surface complexation study of a non-stoichiometric hydroxyapatite. Geochim Cosmochim Acta 2009; 73: 257267.

44) Atkin R, Craig VSJ, Biggs S. Adsorption kinetics and structural arrangements of cetylpyridinium bromide at the silica-aqueous interface. Langmuir 2001; 17: 6155-6163.

45) Xu HHK, Moreau JL, Sun L, Chow LC. Nanocomposite containing amorphous calcium phosphate nanoparticles for caries inhibition. Dent Mater 2011; 27: 762-769.

46) Dickens SH, Flaim GM, Takagi S. Mechanical properties and biochemical activity of remineralizing resin-based Ca-PO4 cements. Dent Mater 2003; 19: 558-566.

47) Langhorst SE, O’Donnell JN, Skrtic D. In vitro remineralization of enamel by polymeric amorphous calcium phosphate composite: quantitative microradiographic study. Dent Mater 2009; 25: 884-891.

48) Moreau JL, Sun L, Chow LC, Xu HHK. Mechanical and acid neutralizing properties and inhibition of bacterial growth of amorphous calcium phosphate dental nanocomposite. J Biomed Mater Res B 2011; 98: 80-88. 